\title{
Propriedades enzimáticas da enzima ALS de Cyperus difformis e mecanismo de resistência da espécie ao herbicida pyrazosulfuron-ethyl
}

\author{
Enzymatic properties of Cyperus difformis ALS enzyme and mechanism resistance of the species to \\ pyrazosulfuron-ethyl herbicide
}

\author{
Taísa Dal Magro ${ }^{\mathrm{I}}$ Sebastião Tavares de Rezende ${ }^{\mathrm{II}}$ Dirceu Agostinetto ${ }^{\mathrm{III}}$ Leandro Vargas $^{\mathrm{IV}}$ \\ Antônio Alberto da Silva ${ }^{\mathrm{V}}$ Daniel Luciano Falkoski $^{\mathrm{VI}}$
}

\section{RESUMO}

Cyperus difformis L. é uma planta daninha ocorrente em lavouras de arroz irrigado, que tem apresentado dificuldade de controle devido à resistência a herbicidas inibidores da enzima ALS. Os objetivos deste trabalho foram investigar caracteristicas cinéticas da enzima ALS de biótipos de $\boldsymbol{C}$. difformis e determinar as bases bioquímicas da resistência da espécie ao herbicida pyrazosulfuron-ethyl. Para isso, foram conduzidos experimentos em laboratório do BIOAGRO/UFV. O método utilizado baseou-se na metologia utilizada por CAREY et al. (1997) e adaptada por VARGAS et al. (1999), com algumas modificações. Foram avaliadas a concentração de substrato (piruvato) que fornece velocidade inicial igual à metade da velocidade máxima de reação $\left(K_{M}\right)$ e velocidade máxima de reação $\left(V_{\max }\right)$, bem como a atividade da enzima ALS na presença do inibidor (pyrazosulfuron-ethyl). Diante dos resultados, pode-se observar que a resistência de $\boldsymbol{C}$. difformis a pyrazosulfuron-ethyl é decorrente da insensibilidade da enzima ALS ao herbicida, não acarretando, porém, prejuizo aos parâmetros cinéticos $K_{M}$ e $V_{\text {max }}$ da enzima $A L S$.

Palavras-chave: acetolactato sintase, arroz irrigado, enzima, junquinho.

\section{ABSTRACT}

Cyperus difformis $L$. is a weed that occurs in flooded rice, which has presented difficulty in controlling due to the resistance to ALS inhibiting herbicides. The objectives of this research were to investigate kinetic characteristics of $A L S$ enzyme from $\boldsymbol{C}$. difformis biotypes and to determine the biochemical bases of resistance from the species to pyrazosulfuron-ethyl herbicide. For that, experiments were conducted at the BIOAGRO/UFV laboratory. The method used was based on the methodology used by CAREY et al. (1997) and adapted by VARGAS et al. (1999), with some modifications. It was evaluated substratum concentration (pyruvate) that provides initial velocity equal to half the speed reaction $\left(K_{M}\right)$ and maximum velocity of reaction $\left(V_{\max }\right)$, as well the activity of the ALS enzyme in the presence of the inhibitor (pyrazosulfuronethyl). According to the results, it is possible to observe that $\boldsymbol{C}$. difformis resistance to pyrazosulfuron-ethyl is due to the insensibility of the ALS enzyme to the herbicide, however without penalty to $K_{M}$ and $V_{\max }$ kinetic parameters of the ALS enzyme.

Key words: acetolactate synthase, enzyme, flooded rice, smallflower umbrella sedge.

\section{INTRODUÇÃO}

Os herbicidas inibidores da enzima acetolactato sintase (ALS) representam o maior grupo de herbicidas em uso no mercado (DEVINE \& SHUKLA, 2000), por apresentarem amplo espectro de controle de plantas daninhas, serem utilizados em

\footnotetext{
'Departamento de Fitossanidade (DFs), Faculdade de Agronomia Eliseu Maciel (FAEM), Universidade Federal de Pelotas (UFPel), Pelotas, RS, Brasil e Curso de Agronomia da Universidade de Caxias do Sul (UCS), Vacaria, RS, Brasil, 95200-000. E-mail: taisadm@yahoo.com.br. Autor para correspondência.

"Departamento de Bioquímica e Biologia Molecular, Centro de Ciências Biológicas e da Saúda, Universidade Federal de Viçosa (UFV), Viçosa, MG, Brasil.

IIIDepartamento de Fitossanidade, FAEM, UFPel, Pelotas, RS, Brasil.

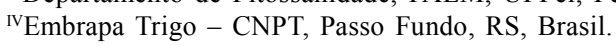

v'Departamento de Fitotecnia, Centro de Ciências Agrárias, UFV, Viçosa, MG, Brasil.

${ }^{\mathrm{v}}$ Bioquímica Agrícola, UFV, Viçosa, MG, Brasil.
} 
baixas doses e por serem também altamente seletivos às culturas (ROMAN et al., 2007).

A enzima ALS, também conhecida como acetohidroxiacido sintase (AHAS), atua na rota da síntese dos aminoácidos valina, leucina e isoleucina (DEVINE \& SHUKLA, 2000), a qual representa o local de ação de muitos herbicidas, como os pertencentes aos grupos químicos das imidazolinonas, pyrimidiltiobenzoatos, sulfoanilidas, sulfoniluréias e trazolopirimidinas (ROMAN et al., 2007).

O controle de plantas daninhas é realizado quase exclusivamente com herbicidas, o que aumentou o número de casos de resistência de plantas daninhas, entre elas, as resistentes a herbicidas inibidores de ALS, que representam cerca de $52 \%$ dos casos registrados mundialmente (HEAP, 2009). O panorama brasileiro não se distingue do mundial, onde os herbicidas inibidores de ALS perfazem 47\% dos casos de resistência (HEAP, 2009).

Dentre os mecanismos de resistência, a alteração do local de ação contempla a maioria dos casos elucidados de resistência aos inibidores de ALS (TAN \& MEDD, 2002; WARWICK et al., 2005; CHRISTOFFERS et al., 2006; TRUCCO et al., 2006; LAMEGO, 2008).

Alterações no local de ação geralmente decorrem de mutações nos genes que codificam a enzima (DEVINE \& SHUKLA, 2000), resultando em redução da afinidade da enzima com os inibidores, porém com ausência ou reduzida perda da função enzimática (TRANEL\& WRIGHT, 2002). Dessas alterações, foram encontrados seis aminoácidos conservados, que, na substituição, tornaram-se responsáveis pela resistência, sendo eles: alanina 122 (Ala122), alanina 205 (Ala205), prolina 197 (Pro197), serina 653 (Ser653), triptofano 574 (Trp574) (TRANEL \& WRIGHT, 2002) e aspartato (Asp376) (WHALEY et al., 2007).

Outros possíveis efeitos decorrentes de mutação na enzima ALS poderão ser alterações nas características cinéticas da enzima, como na concentração de substrato (piruvato), que fornece velocidade inicial igual à metade da velocidade máxima de reação $\left(\mathrm{K}_{\mathrm{M}}\right)$ e a quantidade do inibidor necessária para inibir $50 \%$ da atividade da enzima $\left(\mathrm{I}_{50}\right)$. Em estudos realizados para determinar o $\mathrm{K}_{\mathrm{M}}$ da enzima ALS em biótipos resistentes e suscetíveis, observaram-se, em geral, valores similares (EBERLEIN et al., 1997; VARGAS et al., 1999), demonstrando que não há perda de funções enzimáticas decorrentes da resistência do biótipo. No entanto, quando se refere ao $I_{50}$, é possível observar que o biótipo resistente apresentou, em geral, valores superiores ao suscetível (VARGAS et al., 1999; TRUCCO et al., 2006; LAMEGO, 2008), sugerindo que a resistência é decorrente de alteração na sensibilidade da enzima pelo inibidor.

As hipóteses desta pesquisa são as de que o biótipo de $\boldsymbol{C}$. difformis resistente a herbicidas inibidores de ALS não difere do biótipo suscetível quanto às características cinéticas da ALS e que o mecanismo de resistência decorre da insensibilidade da enzima ao herbicida.

Assim, o objetivo da pesquisa foi investigar características cinéticas da enzima ALS em biótipos de C. difformis e determinar as bases bioquímicas da resistência da espécie a herbicidas inibidores de ALS.

\section{MATERIAL E MÉTODOS}

O material vegetal consistiu de sementes de C. difformis resistentes e suscetíveis aos herbicidas inibidores de ALS, oriundas do Município de Meleiro $\left(49^{\circ} 33^{\prime} \mathrm{LW}\right.$ e $\left.28^{\circ} 53^{\prime} \mathrm{LS}\right)$, que resistiram a aplicações de 16 vezes a dose comercial de pyrazosulfuron-ethyl $(20 \mathrm{~g}$ $\mathrm{ha}^{-1}$ ) e do município de Itajaí ( $48^{\circ} 45^{\prime} \mathrm{LW}$ e $26^{\circ} 56^{\prime} \mathrm{LS}$ ), ambos no Estado de Santa Catarina (SC).

O método empregado baseou-se na metologia utilizada por CAREY et al. (1997) e adaptada por VARGAS et al. (1999), com algumas modificações. Foram utilizados $20 \mathrm{~g}$ de material vegetal (folhas jovens), congelado em nitrogênio líquido $\left(\mathrm{N}_{2}\right)$ e macerado em almofariz. Ao material macerado, foram acrescidos $80 \mathrm{~mL}$ (1:4 p/v) do tampão de extração fosfato $100 \mathrm{mM}$, com $\mathrm{pH} 7,5, \mathrm{a} 4^{\circ} \mathrm{C}$, contendo: $0,5 \mathrm{mM}$ de cloreto de magnésio; $1 \mathrm{mM}$ de piruvato de sódio; $0,5 \mathrm{mM}$ de tiamina pirofosfato (TPP); $10 \mu \mathrm{M}$ de flavina adenina dinucleotídeo (FAD); $10 \%$ v/v de glicerol; $1 \mathrm{mM}$ de ditiotreitol e $5 \%(\mathrm{p} / \mathrm{v})$ de polivinilpolipirolidona (PVPP). Posteriormente, o material foi homogeneizado lentamente e mantido sob agitação por 20 minutos a $4^{\circ} \mathrm{C}$, sendo a mistura filtrada em gaze para remoção e descarte dos resíduos sólidos. A fração líquida foi centrifugada a $12.270 x g$ por 20 minutos, a $4^{\circ} \mathrm{C}$. Após a centrifugação, retirou-se o sobrenadante e o resíduo foi descartado.

Para os bioensaios, in vitro foram preparadas reações em tubos de ensaio, onde cada tubo recebeu $600 \mu \mathrm{L}$ da solução enzimática, volumes variados do substrato ou da solução herbicida e volume de solução tampão para volume final de reação de $1 \mathrm{~mL}$. Foram adicionados ao tratamento zero (testemunha) $50 \mu \mathrm{L}$ de uma solução de $\mathrm{H}_{2} \mathrm{SO}_{4} 3 \mathrm{M}$ para impedir a atividade da enzima. Os valores de absorvância desse tratamento foram descontados dos valores das leituras dos demais. Os experimentos foram realizados em delineamento experimental completamente casualizado, com três repetições. 
Após o preparo da reação, iniciou-se o primeiro período de incubação, por 45 minutos, a $30^{\circ} \mathrm{C}$. Interrompeu-se a reação com adição de $50 \mu \mathrm{L}$ de solução de $\mathrm{H}_{2} \mathrm{~S}_{4} 3 \mathrm{M}$ em cada tubo de ensaio, exceto no controle zero, que já continha o ácido antes da incubação. A segunda incubação, por 15 minutos a $60^{\circ} \mathrm{C}$, foi realizada para a formação da acetoína, a partir da reação do ácido sulfúrico com o acetolactato, formado durante a primeira reação. A etapa seguinte foi realizada para a formação do complexo colorido, onde foram adicionados $1 \mathrm{~mL}$ de solução de creatina $0,5 \% \mathrm{p} / \mathrm{v}$ e $1 \mathrm{~mL}$ de 1 -naphtol $5 \% \mathrm{p} / \mathrm{v}$, preparado em $\mathrm{NaOH} 2,5 \mathrm{M}$ no momento do uso. Após isso, a mistura foi novamente incubada por 15 minutos a $60^{\circ} \mathrm{C}$, para o desenvolvimento da cor, que variou em tons de rosa claro a vermelho claro, contrastando com a cor marromesverdeada do padrão zero. Os tubos foram resfriados à temperatura ambiente e a absorvância lida em espectrofotômetro a $530 \mathrm{~nm}$.

Os valores referentes à atividade da enzima ALS foram apresentados por quantidade de acetoína produzida $\left(\mu \mathrm{mol} \mathrm{min} \mathrm{mL}^{-1}\right)$, determinada pela curva padrão de acetoína. Para a determinação da curva padrão, foram preparadas reações em tubos de ensaio, com três repetições. Cada tubo recebeu 0, 10, 20, 40,60, 80 e $100 \mu \mathrm{M}$ de acetoína e volumes variados da solução tampão para volume final de reação de $1 \mathrm{~mL}$. Para a formação do complexo colorido, foram adicionados $1 \mathrm{~mL}$ de solução de creatina $0,5 \%$ p $/ \mathrm{v}$ e $1 \mathrm{~mL}$ de 1 -naphtol $5 \%$ $\mathrm{p} / \mathrm{v}$, preparado em $\mathrm{NaOH} 2,5 \mathrm{M}$ no momento do uso. A seguir, a mistura foi incubada por 15 minutos a $60^{\circ} \mathrm{C}$, para o desenvolvimento da cor. Os tubos foram resfriados à temperatura ambiente e a absorvância lida em espectrofotômetro a $530 \mathrm{~nm}$. Os valores adotados foram de $0,0058 \mu \mathrm{M}$ de acetoína para cada $\mathrm{nm}$ de absorvância (dados não apresentados).

Os parâmetros cinéticos $\mathrm{K}_{\mathrm{M}} \mathrm{e} \mathrm{V}_{\text {máx }}$ informam a afinidade da enzima com o substrato. Para a obtenção do $\mathrm{K}_{\mathrm{M}} \mathrm{eV}_{\text {máx }}$, os ensaios foram realizados com diferentes concentrações do substrato. Dez concentrações finais de piruvato foram utilizadas: $0,4,8,10,15,25,40,55,75$ e $100 \mathrm{mM}$ para ambos os biótipos (resistente e suscetível). Os valores de $\mathrm{K}_{\mathrm{M}}$ e $\mathrm{V}_{\text {máx }}$ foram determinados a partir da equação de Michaelis Menten (P?0,05) (NELSON \& COX, 2006), conforme segue:

$$
\mathrm{y}=\frac{\mathrm{V}_{\text {máx }} * \mathrm{X}}{\mathrm{K}_{\mathrm{M}}+\mathrm{X}}
$$

em que: $\mathrm{y}=$ atividade da enzima ALS $\left(\mu \mathrm{mol} \cdot \mathrm{min}^{-1} \cdot \mathrm{mL}^{-1}\right)$; $\mathrm{V}_{\text {máx }}=$ velocidade máxima de reação; $\mathrm{x}=$ concentração do substrato (piruvato) e $\mathrm{K}_{\mathrm{M}}=$ concentração de substrato (piruvato) que fornece uma velocidade inicial igual à metade da velocidade máxima de reação. As reações foram realizadas com tempo de 45 minutos de reação para a primeira incubação, temperatura de $30^{\circ} \mathrm{C}$ e pH 7,5 (dados não apresentados).

Foram preparadas duas soluções estoque do herbicida pyrazosulfuron-ethyl (Sirius ${ }^{\circledR}$ ), a $5 \mathrm{mM} \mathrm{e}$ $0,25 \mathrm{mM}$, sendo que a partir dessas soluções foram calculadas as quantidades de herbicida a serem adicionadas em cada tubo de ensaio. Para o biótipo suscetível, as concentrações foram de 0,$0 ; 0,5 ; 1,0 ; 2,5$; $5 ; 10 ; 15 ; 25$ e $50 \mu \mathrm{M}$ e, para o biótipo resistente, as concentrações foram de $0 ; 25 ; 50 ; 100 ; 150 ; 250 ; 500$; 750 e $1000 \mu \mathrm{M}$. O bioensaio conteve dois tratamentospadrão sem o herbicida, denominados 0 (zero) e 100\% (cem) de atividade, sendo que o primeiro recebeu $50 \mu \mathrm{L}$ de solução de ácido sulfúrico $3 \mathrm{M}$ no início do bioensaio, antes da adição do piruvato (substrato) utilizado na concentração de 40 e $35 \mu \mathrm{M}$ para os biótipos resistente e suscetível, respectivamente, e o segundo foi o tratamento padrão correspondendo à testemunha sem inibidor.

Os valores de absorvância foram corrigidos por meio da subtração do valor do controle zero. Os valores obtidos foram usados para calcular o $\mathrm{I}_{50}$, o qual representa a quantidade do inibidor necessária para inibir 50\% da atividade da enzima, utilizando o modelo logístico de regressão não linear (SEEFELDT et al., 1995), conforme segue:

$$
y=\frac{a}{\left(1+\left(x / x I_{50}\right)^{b}\right.}
$$

em que: $\mathrm{y}=$ atividade da enzima ALS (\%); $\mathrm{a}=$ assíntota de máxima; $\mathrm{x}=$ dose do herbicida pyrazosulfuron-ethyl $(\mu \mathrm{M}) ; \mathrm{xI}_{50}=$ dose do herbicida pyrazosulfuron-ethyl $(\mu \mathrm{M})$ correspondente a $50 \%$ da inibição da enzima ALS $\mathrm{e} b=$ declividade da curva.

Foi determinado também o fator de resistência (FR), o qual foi calculado pela divisão do $I_{50}$ do biótipo resistente pelo correspondente ao do biótipo suscetível. O FR expressa o número de vezes em que a dose necessária para inibir 50\% da atividade da enzima do biótipo resistente é superior à dose que inibe 50\% do biótipo suscetível (HALL et al., 1998). Adicionalmente, calculou-se o teor de proteínas totais pelo método de BRADFORD (1976).

\section{RESULTADOS E DISCUSSÃO}

Para os parâmetros cinéticos $\mathrm{K}_{\mathrm{M}}$ (piruvato) e $\mathrm{V}_{\text {máx }}$ da enzima ALS de $\boldsymbol{C}$. difformis, resistente $\mathrm{e}$ suscetível a herbicidas inibidores de ALS, o biótipo resistente apresentou superioridade ao suscetível em 21,5 e 51,9\%, respectivamente (Figura 1). Estes valores podem ser decorrentes da quantidade de enzima 


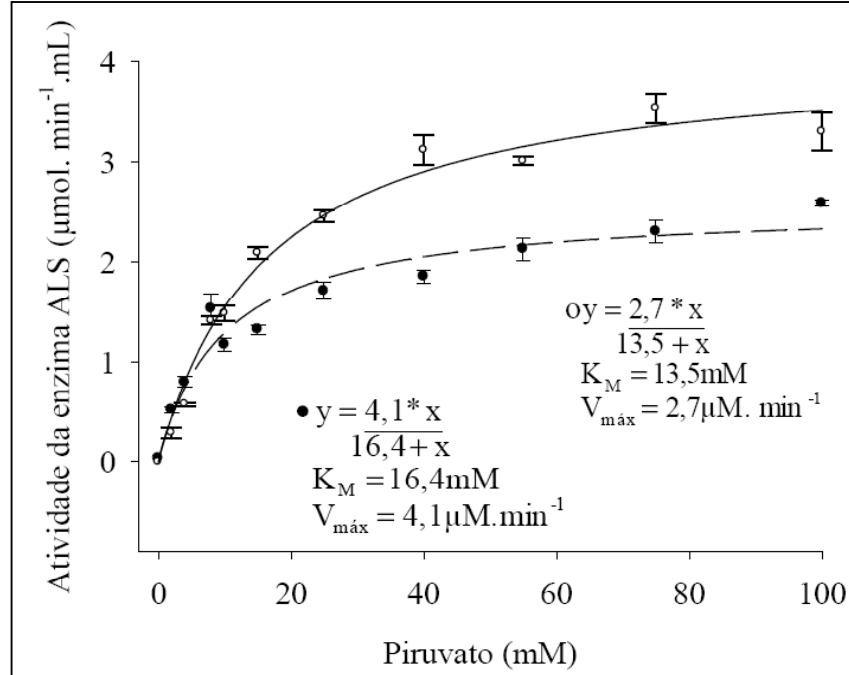

Figura 1 - Atividade da enzima acetolactato sintase (ALS) de Cyperus difformis resistente (O) e suscetível ( O ) ao herbicida pyrazosulfuron-ethyl expressa em produção de acetoína em função de diferentes concentrações de substrato (piruvato). $\mathrm{K}_{\mathrm{M}}=$ concentração de piruvato que fornece a velocidade inicial igual à metade da velocidade máxima de reação e $\mathrm{V}_{\text {maxx }}=$ velocidade máxima da reação. UFV, Viçosa - MG, 2008. (Os pontos representam os valores médios das repetições e as barras verticais os intervalos de confiança).

Diante dos resultados obtidos, evidencia-se que a resistência apresentada pelo biótipo de $\boldsymbol{C}$. difformis a pyrazosulfuronethyl é devida à insensibilidade da enzima ALS a esse herbicida e não é decorrente da superexpressão da mesma.

Biótipos que apresentam resistência decorrente de alteração na composição da enzima ALS apresentam, em geral, elevado fator de resistência, resultante de mutações ocorridas na enzima (DEVINE \& SHUKLA, 2000). Mutações alteram o ponto de acoplamento da enzima ALS, reduzindo a afinidade com os inibidores (TRANEL \& WRIGHT, 2002). DEVINE \& SHUKLA(2000) relatam que a substituição da Prolina na posição 197 resultou em alto nível de resistência a herbicidas do grupo das sulfonilureias em diversas espécies.

Elevado fator de resistência pode inviabilizar o controle de $\boldsymbol{C}$. difformis com herbicidas inibidores de ALS, que é o principal grupo de herbicidas recomendados para manejo da espécie (SOCIEDADE..., 2007).

presente no ensaio, que foi $59 \%$ superior no biótipo resistente, determinado pelo teste de proteína - Bradford (dados não apresentados).

Trabalhos realizados com ALS de $\boldsymbol{E}$. heterophyla (VARGAS et al., 1999), Lactuta serriola (EBERLEIN et al., 1997) e Scirpus juncoides (TANAKA, 2003) demonstraram resultados semelhantes aos observados para $\boldsymbol{C}$. difformis, nos quais a cinética da enzima do biótipo resistente a herbicidas inibidores de ALS não foi alterada, descartando a hipótese de resistência decorrente de "superexpressão" da enzima ALS.

A atividade da enzima ALS, extraída do biótipo de $\boldsymbol{C}$. difformis suscetível, foi inibida pelo herbicida pyrazosulfuron-ethyl, apresentando $\mathrm{I}_{50}$ de $0,57 \mu \mathrm{M}$ (Figura 2A). Entretanto, para o biótipo resistente, foram necessárias doses maiores do herbicida para ocorrer inibição, sendo o valor do $\mathrm{I}_{50}$ de $73,38 \mu \mathrm{M}$ (Figura 2B). Dessa forma, a dose de pyrazosulfuron-ethyl necessária para inibir $50 \%$ da atividade da ALS do biótipo resistente foi 128,7 vezes a dose necessária para o biótipo suscetível (Tabela 1).
Entre os fatores responsáveis pelo aumento dos casos de resistência a este grupo de ação, encontram-se as características desses herbicidas, tais como utilização em baixas doses e alta seletividade às culturas (ROMAN et al., 2007). Ainda, o aumento de casos pode decorrer do desenvolvimento de culturas resistentes a herbicidas inibidores de ALS, o que resulta em acréscimo na pressão de seleção de espécies daninhas (DEVINE \& SHUKLA, 2000). Medidas relacionadas à utilização ponderada de manejo químico de plantas daninhas, como a rotação de mecanismo de ação de herbicidas, tornam-se necessárias para prorrogar o surgimento da resistência.

No presente trabalho, verificou-se que não houve prejuízo à atividade da enzima ALS de $\boldsymbol{C}$. difformis oriundo de lavouras orizícolas de Santa Catarina, o que permite inferir que a resistência decorre de mutações nos genes que codificam a enzima. Resultados semelhantes encontram-se na literatura para resistência aos herbicidas inibidores de ALS em Amaranthus hybridus (TRUCCO et al., 2006), B. subalternans (LAMEGO, 2008) e R. raphanistrum (TAN \& MEDD, 2002). 


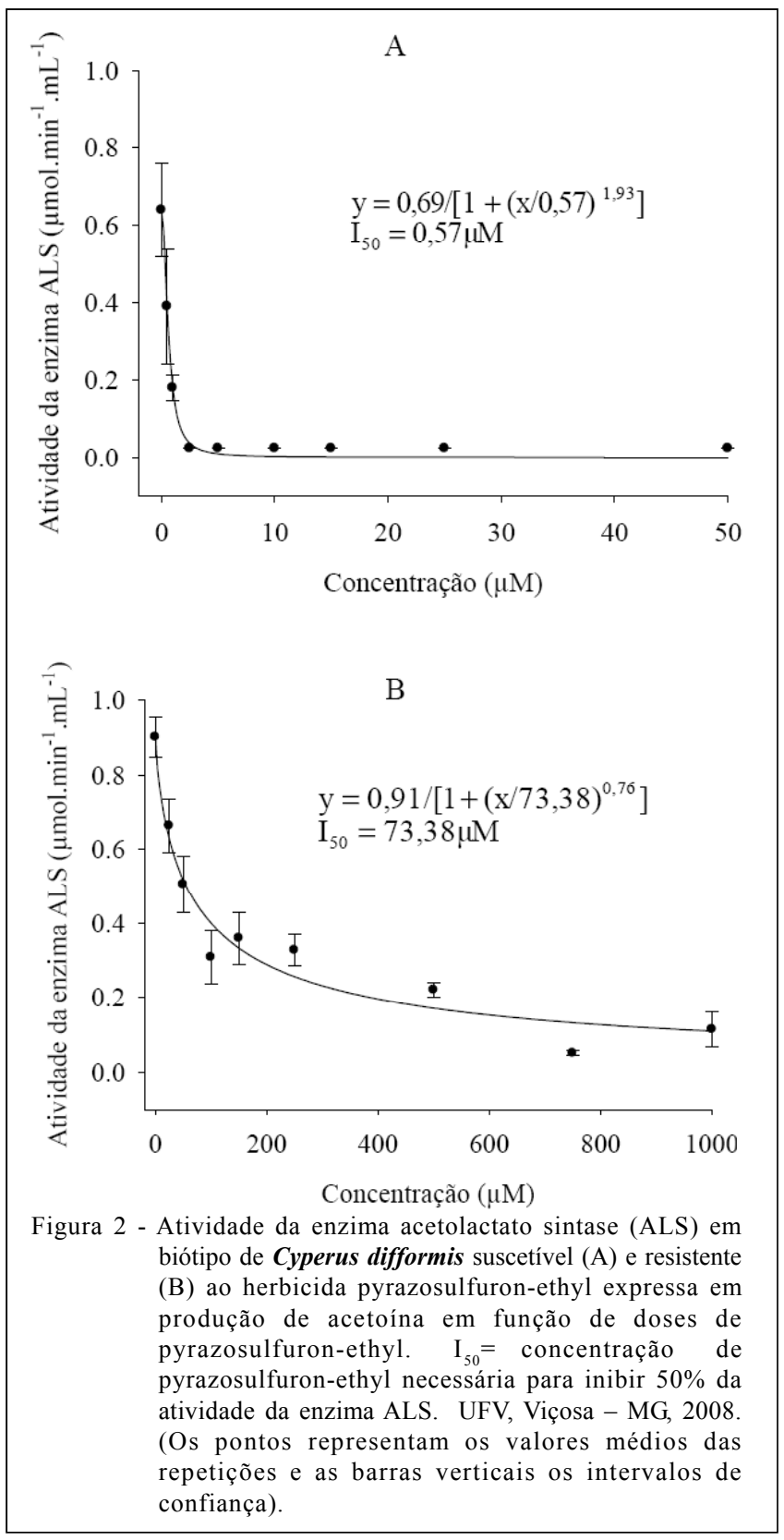

Tabela 1 - Concentração do herbicida pyrazosulfuron-ethyl necessária para inibir $50 \%$ da atividade da enzima acetolactato sintase (ALS) $\left(\mathrm{I}_{50}\right)$ de Cyperus difformis em biótipos resistente e suscetível e o respectivo fator de resistência (FR). UFV, ViçosaMG, 2008.

\begin{tabular}{ll}
\hline Biótipos & $\mathrm{I}_{50}(\mu \mathrm{M})^{(1)}$ \\
\hline Resistente & 73,38 \\
Suscetível & 0,57 \\
$\mathrm{FR}^{(2)}$ & 128,74 \\
\hline
\end{tabular}

${ }^{(1)}$ Dados obtidos pela equação sigmoidal $\mathrm{y}=\mathrm{a} /\left(1+\left(\mathrm{x} / \mathrm{xa} \mathrm{a}_{50}\right)^{\mathrm{b}}\right)$, $(\mathrm{P} \leq 0,05) .{ }^{(2)}$ Fator de resistência $=\mathrm{I}_{50} \mathrm{R} / \mathrm{I}_{50} \mathrm{~S}$.

\section{CONCLUSÃO}

A resistência de Cyperus difformis ao herbicida pyrazosulfuron-ethyl não altera os parâmetros cinéticos $\mathrm{K}_{\mathrm{M}}$ (concentração de piruvato que fornece a velocidade inicial igual à metade da velocidade máxima de reação) e $\mathrm{V}_{\text {máx }}$ (velocidade máxima da reação) da enzima ALS. A resistência do biótipo de $\boldsymbol{C}$. difformis a pyrazosulfuron-ethyl decorre da insensibilidade da enzima ALS ao herbicida.

\section{REFERÊNCIAS}

BRADFORD, M.M. A rapid and sensitive method for the quantitation of microgram quantities of protein utilizing the principle of protein-dye binding. Analytical Biochemistry, v.72, p.248-254, 1976.

CAREY, J.B. et al. Physiological basis for nicosulfuron and primisulfuron selectivity in five plant species. Weed Science, v.45, p.22-30, 1997.

CHRISTOFFERS, M.J. et al. Target-site resistance to acetolactate synthase inhibitors in wild mustard (Sinapis arvensis). Weed Science, v.54, p.191-197, 2006.

DEVINE, M.D.; SHUKLA, A. Altered target sites as a mechanism of herbicide resistance. Crop Protection, v.19, p.881-889, 2000. Disponível em: <http:// w w w. s c i e n c e d i r e c t. c o m / science?_ob=ArticleURL\&_udi=B6T5T-41J6698$1 \mathrm{~W} \&$ u s e r $=2614326 \& \&_{-}$c over D a t e $=$ $09 \% 2$ F $12 \% 2$ F $2000 \&$ rdoc $=1 \&$ f m t $=$ hig $\mathrm{h} \&$ _orig $=$ search\&_sort $=\mathrm{d} \&$ _docanchor $=\&$ view $=\mathrm{c} \&$ _searchStrId $=14$ 43361218 \&_re r u n Orig i n $=$ g o o g 1 e $\&$ acct $=$ C000058070\&_version $=1 \&$ urlVersion $=0 \&$ userid $=26143$ $2 \overline{6} \& \mathrm{md} 5=\mathrm{f} 3 \mathrm{ab} 0 \mathrm{~d} 3 \mathrm{c} 82 \mathrm{dc} 59 \overline{2} 0 \mathrm{~cd} 7 \mathrm{ce} 7 \mathrm{a} 4 \mathrm{efff} 0 \mathrm{e} 54>$. Acesso em: 02 fev. 2009. doi: 10.1016/S02612194(00)00123-x.

EBERLEIN, C.V. et al. Altered acetolactate synthase activity in ALS-inibitor resistant prickly lettuce (Lactuca serriola). Weed Science, v.45, p.212-217, 1997.

HALL, L.M. et al. Resistance to acetolactato sintase inhibithors and quinclorac in a biotypes of false clover (Gallium sourium). Weed Science, v.46, p.390-396, 1998.

HEAP, I. The International Survey of Herbicide Resistant Weeds. Disponível em: http://www.weedscience.org. Acesso em: 8 jan. 2009.

LAMEGO, F.P. Elucidação do mecanismo de resistência aos herbicidas inibidores de ALS na espécie poliplóide Bidens subalternans DC. 2008. 152f. Tese (Doutorado em Fitotecnia) - Curso de Pós-graduação em Fitotecnia, Universidade Federal do Rio Grande do Sul.

NELSON, D.L.; COX, M.M. Lehninger princípio de bioquímica. 4.ed. São Paulo: SARVIER, 2006. p.190-235. 
ROMAN, E.S. et al. Como funcionam os herbicidas: da biologia à aplicação. Passo Fundo: Berthier, 2007. 160p.

SEEFELDT, S.S. et al. Log-logistic analysis of herbicide doseresponse relationships. Weed Technology, v.9, p.218-227, 1995.

SOCIEDADE SUL-BRASILEIRA DE ARROZ IRRIGADO [SOSBAI]. Arroz irrigado: recomendações técnicas da pesquisa para o Sul do Brasil. Pelotas: Sosbai, 2007. 161p.

TAN, M.K.; MEDD, R.W. Characterisation of the acetolactate synthase (ALS) gene of Raphanus raphanistrum L. and the molecular assay of mutations associated with herbicide resistance. Plant Science, v.163, p.195-205, 2002. Disponível em: <http://www.sciencedirect.com/ science?_ob=ArticleURL\&_udi=B6TBH-46H0N65$1 \&$ user $=2614326 \&$ coverDate $=08 \% 2 \mathrm{~F} 31 \% 2 \mathrm{~F} 2002 \&$ rdoc $=1 \&$ f $\overline{\mathrm{m}} \mathrm{t}=\mathrm{high} \&$ orig $=$ search\&_origin $=$ search $\&$ _sort $=$ $\mathrm{d} \&$ docanchor $=\&$ view $=\mathrm{c} \&$ searchStrId $=1449022320$ \&_rerunOrigin =google\&_ac c t $=$ C 00005807 $0 \&$ version $=1 \&$ urlVersion $=0 \&$ user $\quad \mathrm{id}=2614326 \& \mathrm{md} 5=2$ e10e7a1301c519c3ab49065f9bcc8fe \&searchtype $=\mathrm{a}>$. Acesso em: 02 fev. 2009. doi: 10.1016/S01689452(02)00082-1.

TANAKA, Y. Properties of acetolactate synthase from sulfonylurea-resistant Scirpus juncoides Roxb. var. ohwianus T. Koyama. Pesticide Biochemistry and Physiology, v.77, p.147-153, 2003. Disponível em: <http://www.sciencedirect.com/ science?_ob=ArticleURL\&_udi=B6WP8-49HMTN6$2 \& \quad$ u s e r $=2614326 \& \quad$ c o v e r D a t e $=1$ $1 \% 2$ F $30 \% 2$ F $2003 \&$ r do c $=1 \&$ f m t $=h$ igh \&_orig $=$ search\&_origin $=$ search \&_sort $=\mathrm{d} \&$ docanchor $=\&$ vie $\mathrm{w}=\mathrm{c} \&$ _s e a r ch S trId $=1449028446 \&$ re run
Origi n $=$ g o o g 1 e \&_a c c t $=$ C $0000058070 \&$ version $=1 \&$ urlVersion $=0 \&$ userid $=2614326 \& \mathrm{md}$ $5=88863 \mathrm{~b} 8 \mathrm{ae} 249 \mathrm{~d} 56 \mathrm{~b} 2942899 \mathrm{~b} 97 \mathrm{~d} 51568 \&$ searchtype $=\mathrm{a}>$. Acesso em: 28 jan. 2009. doi: 10.1016/j.pestbp.2003.07.005.

TRANEL, P.J.; WRIGHT T.R. Resistance of weeds to ALSinhibiting herbicides: what have we learned? Weed Science, v. 50, p. $700-712,2002$.

TRUCCO, F. et al. Acetolactate synthase mutation conferring imidazolinone-specific herbicide resistance in Amaranthus hybridus. Journal of Plant Physiology, v.163, p.475-479, 2006. Disponível em: <http://www.sciencedirect.com/ science? ob=ArticleURL\& udi=B7GJ7-4H392SF$4 \&$ \& s e r $=2614326 \&$ \& coverDate $=03 \% 2 \mathrm{~F} 31 \% 2 \mathrm{~F}$ $2006 \&$ rdoc $=1 \&$ fmt $=$ high $\&$ orig $=$ search $\&$ origin $=$ search $\&$ sort $=$ d\&_docanchor $=\&$ view $=$ c\&_searchStrId $=1$ $\overline{4} 49032 \overline{2} 66$ \& r e r un Orig i $\bar{n}=$ g o o g 1 e \& acct $=\mathrm{C} 000058070 \&$ version $=1 \&$ urlVersion $=0 \&$ u s e r i d $=2614326 \& \mathrm{~m} \mathrm{~d} 5=\mathrm{b} d 366959 \overline{\mathrm{d}}$ fbd33f2291184050b9516ad\&searchtype $=\mathrm{a}>$. Acesso em: 03 fev. 2009. doi: 10.1016/jplph.2005.06.015.

VARGAS, L. et al. Resistência de plantas daninhas a herbicidas. Viçosa: JARD Prod., 1999. 131p.

WARWICK, S.I. et al. Resistance in Canadian biotypes of wild mustard (Sinapis arvensis) to acetolactate synthase inhibiting herbicides. Weed Science, v.53, p.631-639, 2005 .

WHALEY, C.M. et al. A new mutation in plant ALS confers resistance to five classes of ALS-inhibiting herbicides. Weed Science, v.55, p.83-90, 2007. 